\title{
Sistem Pendeteksi Jatuh Wireless Berbasis Sensor Accelerometer
}

\author{
Gigih Gumilar ${ }^{1}$, Hendi Handian Rachmat ${ }^{2}$ \\ ${ }^{1,2}$ Jurusan Teknik Elektro, Institut Teknologi Nasional Bandung \\ Jln. P.H.H. Mustapa No. 24 Bandung, telp/fax 022-7272215 \\ giehxpose@gmail.com ${ }^{1}$, hendi.elite@gmail.com ${ }^{2}$
}

\begin{abstract}
Abstrak - Pada penelitian ini, sensor accelerometer digunakan sebagai sistem pendeteksi jatuh secara real time, wearable dan ambulatory guna memudahkan pengawasan pada lansia ketika posisi jatuh. Sistem ini terdiri dari dua bagian yaitu bagian pengirim dan bagian penerima yang masing-masing dilengkapi sistem komunikasi wireless, dengan frekuensi radio $2,4 G H z$ untuk mengirimkan data kondisi jatuh antara kedua bagian tersebut. Sensor accelerometer digunakan pada bagian pengirim untuk mendeteksi nilai tiga sumbu percepatan gravitasi dan nilai magnitude pada saat terjadi kondisi jatuh guna selanjutnya diolah pada Arduino Nano. Sistem pengirim ditempatkan pada pinggang naracoba untuk diuji dalam mendeteksi 2 tipe jatuh yaitu jatuh ke depan dan jatuh ke belakang. Dari hasil pengujian pada 10 naracoba dengan rentang usia 21-24 tahun didapatkan bahwa karakteristik tiga sumbu pada posisi jatuh ke depan bernilai 0,123g, -0,473g, -0,888g dan ke belakang bernilai -0,084g, 0,495g, 0,628g. Adapun nilai rata-rata magnitude pada jatuh ke depan bernilai 2,916g dan ke belakang bernilai $2,580 \mathrm{~g}$.
\end{abstract}

Kata Kunci: Accelerometer, Ambulatory, Jatuh, Wearable, Wireless.

\section{Pendahuluan}

Jatuh merupakan kejadian yang berbahaya bagi manusia karena dapat berpengaruh terhadap kerusakan serta kesehatan tubuh. Terutama bagi orang yang sudah lanjut usia (lansia), jatuh dapat menimbulkan dampak yang sangat fatal. Resiko jatuh pada lansia terbilang lebih tinggi jika dibandingkan dengan usia muda. Hal ini dikarenakan fungsi otak pada lansia sudah mulai menurun dan terjadi keterbatasan gerak [1]. Jatuh menjadi ancaman yang paling diantisipasi pada lansia karena berpotensi menyebabkan kematian.

Berdasarkan survei yang dilakukan oleh WHO, 28\%-35\% dari lansia yang berusia lebih dari 60 tahun di seluruh dunia mengalami jatuh setiap tahunnya. Kecelakaan akibat jatuh yang terjadi sekitar 20\%-30\% lansia memerlukan perawatan luka ringan sampai dengan parah, dan 10\%-15\% memerlukan perawatan gawat darurat. Adapun kematian akibat jatuh terjadi sekitar $20 \%$ pada lansia. Selain itu, jatuh juga dapat mengakibatkan post-fall syndrome, kehilangan otonomi, kebingungan, dan depresi yang akan berdampak pada keterbatasan aktivitas sehari-hari [2]. Dengan demikian jatuh menjadi hal yang sangat diantisipasi bagi lansia.

Dengan kondisi tersebut, maka diperlukan pengawasan aktivitas keseharian pada lansia. Melalui pengawasan tersebut, maka diharapkan ketika terjadi jatuh maka respon penanganan dapat dilakukan dengan cepat. Pengawasan terhadap lansia dapat dilakukan secara manual maupun secara otomatis dengan bantuan alat pendeteksi jatuh. Pengawasan secara manual memiliki keterbatasan yaitu memerlukan usaha dan tenaga manusia (perawat) yang lebih karena harus dilakukan selama 24 jam, sedangkan pengawasan menggunakan alat pendeteksi jatuh elektronik yang bekerja secara otomatis menjadi salah satu solusi untuk mengefektifkan pengawasan.

TELKA, Vol.4, No.2, November 2018, pp. 132 141

ISSN (e): 2540-9123

ISSN (p): 2502-1982 
Salah satu alat pendeteksi jatuh yang dapat diimplementasikan adalah dengan menggunakan sensor Inertial Measurement Unit (IMU). IMU adalah instrumentasi elektronik yang digunakan untuk mengukur kecepatan, orientasi, dan gaya gravitasi dengan menggunakan accelerometer dan gyroscope. IMU biasanya berisi tiga tingkatan ortogonal (tegak lurus dengan bidang lainnya) gyroscope dan tiga tingkatan ortogonal (tegak lurus dengan bidang lainnya) accelerometer, dimana secara berturut-turut berfungsi untuk mengukur kecepatan sudut dan percepatan linear masing-masing [3]. Telah dilakukan pengembangan alat pendeteksi jatuh perangkat yang wearable dan wireless dengan akurasi $99,49 \%$ dan presisi $81 \%$ namun modul komunikasi hanya mampu mengirim data sejauh 20 meter [4]. Alat pendeteksi jatuh lainya yang telah dikembangkan memiliki akurasi sebesar $98.182 \%$, kepresisian sebesar 98.33\%, sensitivitas sebesar $95.161 \%$, dan spesifisitas sebesar $99.367 \%$ namun pemantauan tidak dilakukan secara real time [5].

Pada penelitian ini dilakukan pengembangan alat pendeteksi jatuh berbasis sensor accelerometer dengan sifat sistem yaitu: ambulatory, wearable, real time dan pengembangan secara wireless sebagai komunikasi data antara sensor dengan penampil. Alat pendeteksi jatuh ini berbasis mikrokontroler sebagai pengolah data dari sensor accelerometer yang bertujuan untuk mengevaluasi tipe jatuh seorang naracoba atau pasien dan mengirimkan data kondisi jatuh tersebut ke unit penerima secara wireless. Tipe jatuh yang dievaluasi yaitu jatuh ke depan dan jatuh ke belakang. Keluaran dari penelitian ini diharapkan diperoleh sejumlah parameter yang dapat mencirikan kondisi jatuh dan posisi jatuh yang terjadi pada naracoba atau pasien guna penangan yang lebih optimal setelah terjadi jatuh.

\section{Metodologi Penelitian}

\subsection{Spesifikasi dan Diagram Blok Sistem}

Sistem pendeteksi jatuh dirancang secara optimal agar memungkinkan untuk dapat mengirimkan data secara wireless. Untuk memungkinkan pengawasan terhadap naracoba yang sedang beraktifitas maka sistem dibuat agar dapat bersifat real time, wearable dan ambulatory. Adapun spesifikasi alat yang diimplementasikan yaitu:

1. Sensor accelerometer berupa modul terintegrasi MPU6050,

2. Modul kontrol unit berupa Arduino Nano,

3. Modul komunikasi pengirim dan penerima berupa nRF24L01 dengan jarak komunikasi data wireless berjarak optimal 100 meter,

4. Pemantauan dilakukan secara real time,

5. Ambulatory dengan catudaya berupa baterai 9Volt DC,

6. Wearable dengan penempatan sistem pada pinggang naracoba,

7. Penampil yang digunakan masih menggunakan tampilan layar Personal Computer (PC) melalui serial monitor.

Sistem pendeteksi jatuh ini terdiri dari dua bagian yaitu bagian pengirim dan bagian penerima, seperti ditunjukkan pada Gambar 1. Pada bagian pengirim sistem ini terdiri dari modul sensor, modul kontrol unit, modul komunikasi dan catu daya. Adapun pada bagian penerima sistem ini terdiri dari modul komunikasi, modul kontrol unit dan PC. Prinsip kerja sederhana dari sistem ini yaitu pertama sensor accelerometer akan mengakuisisi data percepatan gravitasi dari kondisi jatuh yang terjadi. Data tersebut selanjutnya diproses oleh modul kontrol bagian pengirim dan dikirimkan melalui modul komunikasi bagian pengirim menuju modul komunikasi bagian penerima. Setelah data diterima oleh modul komunikasi bagian penerima, data diproses oleh modul kontrol unit bagian penerima untuk dapat menampilkan data kondisi jatuh yang terjadi. Setelah didapatkan data kondisi jatuh yang terjadi, kondisi tersebut akan ditampilkan pada PC atau laptop melalui serial monitor yang terdapat pada modul kontrol unit yang telah terhubung dengan PC atau laptop. 


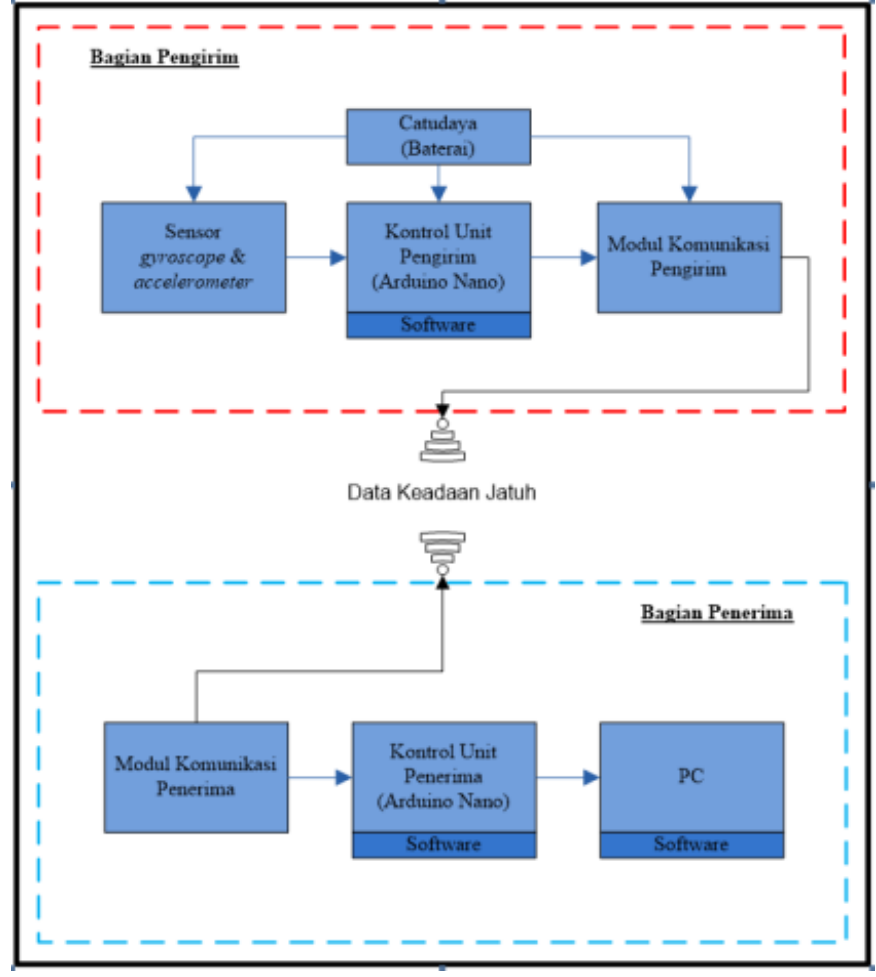

Gambar 1. Diagram blok sistem pendeteksi jatuh

\subsection{Metodologi Perancangan Sistem}

\section{a. Modul Sensor MPU6050}

Modul sensor MPU6050 merupakan alat ukur inersial yang terdiri dari gyroscope dan accelerometer. Sensor ini membutuhkan catu daya sebesar 3,3Volt DC. Pada sistem ini catu daya tersebut diperoleh dari keluaran yang tersedia pada unit kontrol unit Arduino Nano. Pengambilan nilai posisi ini didapatkan dari MEMS (Microelectromechanical systems) yang menggunakan capacitive sensor sebagai pembaca sikap. Nilai-nilai kapasitif yang dihasilkan akan diproses melalui penguatan, pengkondisian sinyal, dan demodulasi sehingga diperoleh besaran elektris berupa tegangan. Besaran tegangan analog yang diperoleh akan diolah melalui 16-bit Analog-to-Digital (ADC) pada masing-masing sumbu gyroscope dan accelerometer sehingga diperoleh sinyal digital dari pembacaan sensor[6]. Pada sistem ini, hanya digunakan data-data pengukuran dari sensor accelerometer. Pada Gambar 2 ditunjukkan bentuk fisik modul sensor MPU6050.

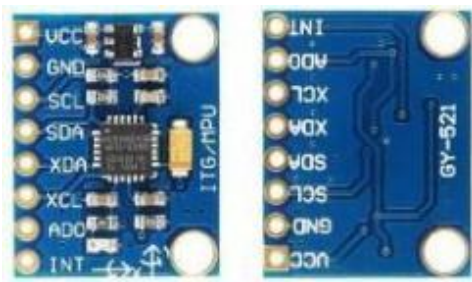

Gambar 2. Bentuk fisik modul sensor MPU6050

Protokol komunikasi yang digunakan untuk melakukan pembacaaan data atau melakukan konfigurasi pada sensor ini adalah protokol komunikasi Inter-Integrated Circuit (I2C). Rentang skala yang dapat diatur pada sensor MPU6050 terdapat pada Tabel 1. Pada sistem ini, rentang skala yang digunakan pada sensor accelerometer sebesar $\pm 2 \mathrm{~g}$. Hal ini mengakibtkan bahwa hasil pengukuran percepatan gravitasi yang diperoleh oleh sistem ini berkisar dari $-2 \mathrm{~g}$ sampai dengan $+2 \mathrm{~g}$. 
Tabel 1. Rentang skala sensor MPU6050

\begin{tabular}{|c|c|c|c|c|}
\hline AFS_SEL & $\begin{array}{c}\text { Rentang Skala Penuh } \\
\text { Accelerometer }\end{array}$ & $\begin{array}{c}\text { Sensitivitas } \\
\text { LSB }\end{array}$ & $\begin{array}{c}\text { Rentang Skala } \\
\text { Penuh Gyroscope }\end{array}$ & $\begin{array}{c}\text { Sensitivitas } \\
\text { LSB }\end{array}$ \\
\hline 0 & $\pm 2 \mathrm{~g}$ & $16384 \mathrm{LSB} / \mathrm{g}$ & $\pm 250 \% \mathrm{~s}$ & $131 \mathrm{LSB} / \mathrm{s}$ \\
\hline 1 & $\pm 4 \mathrm{~g}$ & $8192 \mathrm{LSB} / \mathrm{g}$ & $\pm 500 \% \mathrm{~s}$ & $65.5 \mathrm{LSB} / \% / \mathrm{s}$ \\
\hline 2 & $\pm 8 \mathrm{~g}$ & $4096 \mathrm{LSB} / \mathrm{g}$ & $\pm 1000 \% \mathrm{~s}$ & $32.6 \mathrm{LSB} / \% / \mathrm{s}$ \\
\hline 3 & $\pm 16 \mathrm{~g}$ & $2048 \mathrm{LSB} / \mathrm{g}$ & $\pm 2000 \% \mathrm{~s}$ & $16.4 \mathrm{LSB} / \%$ \\
\hline
\end{tabular}

\section{b. Modul Kontrol Unit Arduino Nano}

Modul kontrol unit yang digunakan pada sistem ini adalah Arduino Nano dengan mikrokontroler berbasis ATmega328P. Arduino Nano digunakan pada bagian pengirim dan bagian penerima sebagai modul kontrol unit utama. Arduino Nano pada sistem ini membutuhkan catu daya sebesar 9Volt DC. Pada sistem ini catu daya tersebut diperoleh melalui satu buah baterai 9Volt DC. Mikrokontroler ATmega328P memiliki fitur protokol komunikasi I2C, Serial Peripheral Interface (SPI), dan universal asynchronous receiver-transmitter (UART). Pada Gambar 3 ditunjukkan pin layout dari modul kontrol unit Arduino Nano.

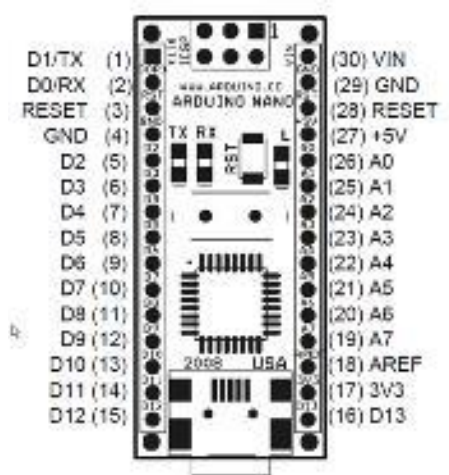

Gambar 3. Kontrol unit Arduino Nano

\section{c. Modul Komunikasi nRF24L01}

Modul nRF24L01 merupakan modul komunikasi yang memanfaatkan gelombang radio dengan frekuensi 2,4 GHz sebagai media untuk berkomunikasi. Modul ini digunakan sebagai modul komunikasi utama untuk berkomunikasi antara bagian pengirim dan bagian penerima. Modul ini membutuhkan catu daya sebesar 3,3Volt DC. Pada sistem ini catu daya tersebut diperoleh dari keluaran yang tersedia pada modul Arduino Nano. Protokol komunikasi yang digunakan untuk berkomunikasi atau melakukan konfigurasi pada sensor ini adalah protokol komunikasi SPI. Pada Gambar 4 ditunjukkan bentuk fisik modul komunikasi nRF24L01.

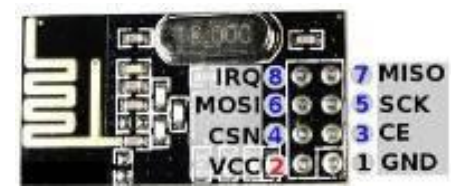

Gambar 4. Bentuk fisik modul komunikasi nRF24L01

\subsection{Metodologi Realisasi Sistem}

\section{a. Integrasi Bagian Pengirim}

Bagian pengirim terdiri dari sensor MPU6050, modul kontrol unit Arduino Nano, modul komunikasi pengirim nRF24L01 dan sebuah catu daya berupa baterai 9Volt. Bagian ini membaca perubahan kecepatan yang dialami naracoba ketika jatuh. Accelerometer pada sensor MPU6050 membaca perubahan kecepatan pada tiga sumbu (x, y, z) pada saat terjadi jatuh. Data perubahan kecepatan tersebut dikirimkan secara wireless menuju bagian penerima 
menggunakan modul komunikasi pengirim berupa nRF24L01. Pada Gambar 5 ditunjukkan diagram alir program pada bagian pengirim secara sederhana.

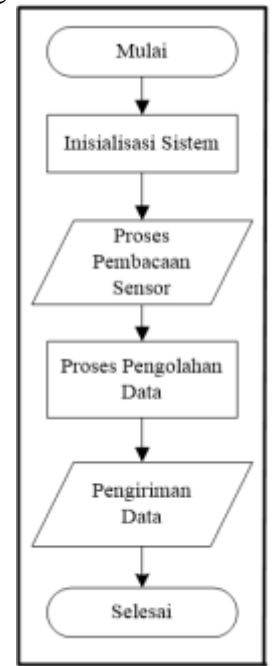

Gambar 5 Diagram Alir Bagian Pengirim

Sensor MPU6050 beroperasi melalui protokol komunikasi I2C, sehingga untuk mengakses sensor MPU6050 menggunakan kontrol unit bagian pengirim, pin SDA dan pin SCL pada modul sensor dan modul kontrol unit harus saling terhubung. Untuk sarana komunikasi tersebut maka pin SDA pada modul sensor dihubungkan pada pin A4 (SDA) dan pin SCL dihubungkan pada pin A5 (SCL) pada Arduino Nano, serta pin AD0 sebagai slave address dihubungkan terhadap ground. Gambar 6 menujukkan skematik rangkaian dari integrasi setiap modul pada bagian pengirim.

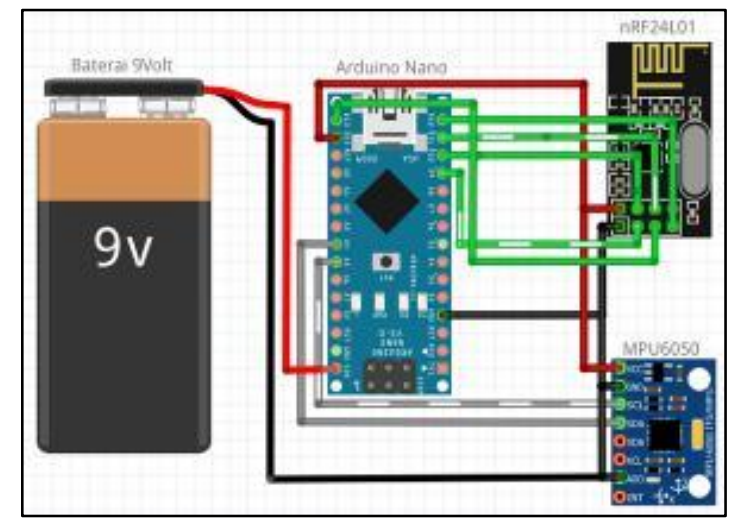

Gambar 6. Skematik rangkaian bagian pengirim

Modul komunikasi bagian pengirim yang digunakan adalah modul nRF24L01. Modul tersebut beroperasi dengan metode SPI untuk dapat berkomunikasi terhadap modul kontrol unit bagian pengirim. Pin-pin SCLK, MISO, dan MOSI pada nRF24L01 dan Arduino Nano harus saling terhubung agar modul komunikasi pengirim dapat berkomunikasi dengan modul kontrol unit. Pin SCLK pada modul komunikasi duhubungkan pada pin D13 (SCK) pada Arduino Nano, MISO pada pin D12 (MISO), dan MOSI pada pin D11 (MOSI). Catu daya yang digunakan adalah satu buah baterai 9Volt. Arduino Nano membutuhkan tegangan masukan dari rentang 6Volt hingga 20Volt [7]. Pin Vin pada Arduino Nano berfungsi sebagai pin tegangan masukan yang sudah dilengkapi rangkaian regulator, sehingga tegangan yang diterima modul kontrol unit adalah sebesar 5Volt.

Realisasi sistem bagian pengirim dapat dilihat pada Gambar 7. Modul dan komponen yang digunakan diintegrasikan ke dalam satu printed circuit board (PCB). Pada PCB terdapat 4 unit 
yang diintegrasikan yakni: modul sensor MPU6050, modul kontrol unit Arduino Nano, modul komunikasi nRF24L01 dan catu daya baterai 9Volt.

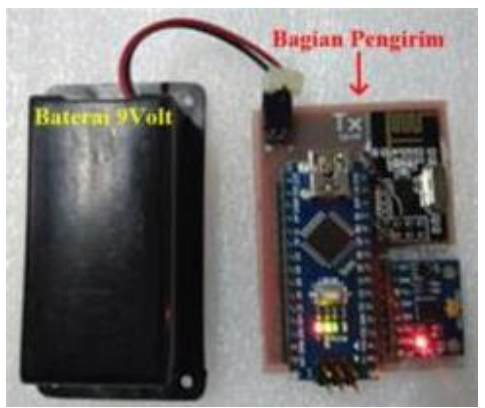

Gambar 7. Realisasi sistem bagian pengirim

\section{b. Integrasi Bagian Penerima}

Bagian penerima terdiri dari modul kontrol unit Arduino Nano, modul komunikasi nRF24L01, dan PC. Bagian ini berfungsi untuk menerima data dari bagian pengirim untuk ditampilkan melalui serial monitor pada PC. Gambar 8 menunjukkan diagram alir bagian penerima.

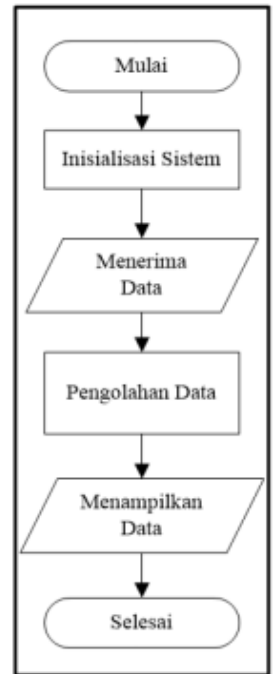

Gambar 8. Diagram alir bagian penerima

Data yang diterima dari bagian pengirim diterima oleh nRF24L01 pada bagian penerima dan dikirimkan pada modul kontrol unit dengan media komunikasi SPI. Gambar 9 menunjukkan skematik rangkaian bagian penerima.

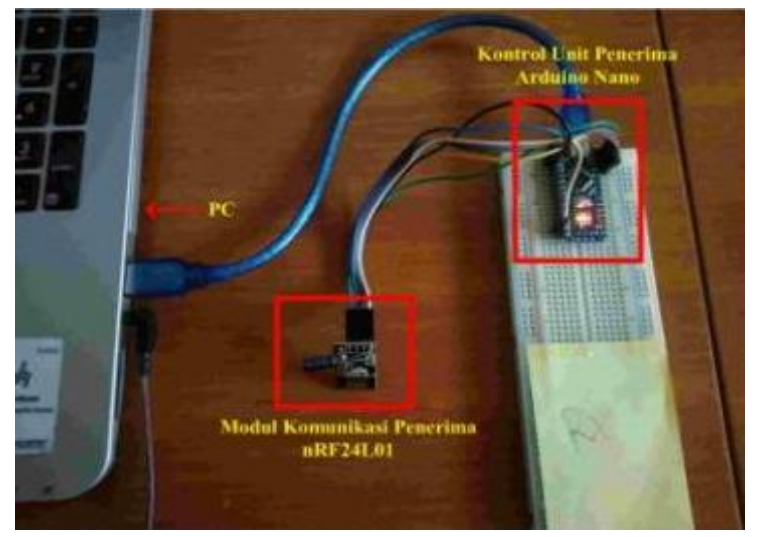

Gambar 9. Realisasi sistem bagian penerima

ISSN (e): 2540-9123 
Persamaan (1) digunakan untuk mengetahui magnitude yang diperoleh dari pengukuran sensor accelerometer. Selanjutnya data hasil pengukuran perubahan kecepatan pada tiga sumbu (x, y, z) dan mangitude yang diperoleh akan ditampilkan melalui serial monitor pada PC.

$$
\text { Magnitude }=\sqrt{\text { gForce } X^{2}+\text { gForce }^{2}+\text { gForce }^{2}}
$$

\subsection{Metodologi Pengujian Sistem}

Pengujian sistem diawali dengan melakukan kalibrasi posisi sistem untuk mengetahui kondisi awal nilai percepatan grafitasi baik untuk sumbu x, sumbu y maupun sumbu z. Setelah dilakukan kalibrasi, selanjutnya dilakukan pengujian pendeteksian kondisi jatuh. Pengambilan data dilakukan dengan cara memasangkan sistem alat pendeteksi jatuh terhadap naracoba. Pada Gambar 10 ditunjukkan letak pemasangan sistem alat pendeteksi jatuh terhadap naracoba yang diletakkan pada bagian pinggang naracoba.

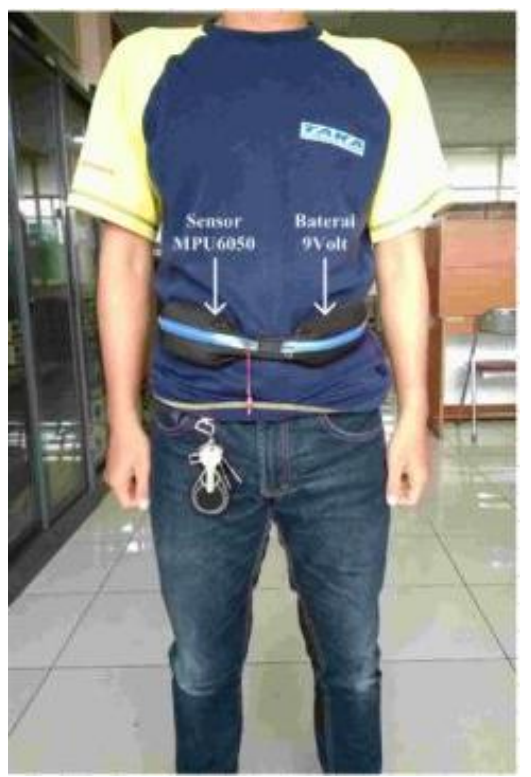

Gambar 10. Diagram alir bagian penerima

Pada tahap pengujian kondisi jatuh dilakukan dengan cara mengambil data percepatan gravitasi pada sensor accelerometer yang sudah dipakai oleh naracoba. Langkah pertama naracoba akan memperagakan sikap berdiri-jatuh yaitu: jatuh ke depan dan jatuh ke belakang. Data yang diperoleh berupa percepatan gravitasi dari masing-masing kondisi jatuh. Pengambilan data dilakukan dengan melibatkan 10 orang naracoba dengan rata-rata usia 22,5 tahun (rentang usia dari 21-24 tahun). Pengujian dilakukan dengan pengulangan 3 kali pada masing-masing naracoba. Ilustrasi pengujian jatuh diperlihatkan pada Gambar 11.

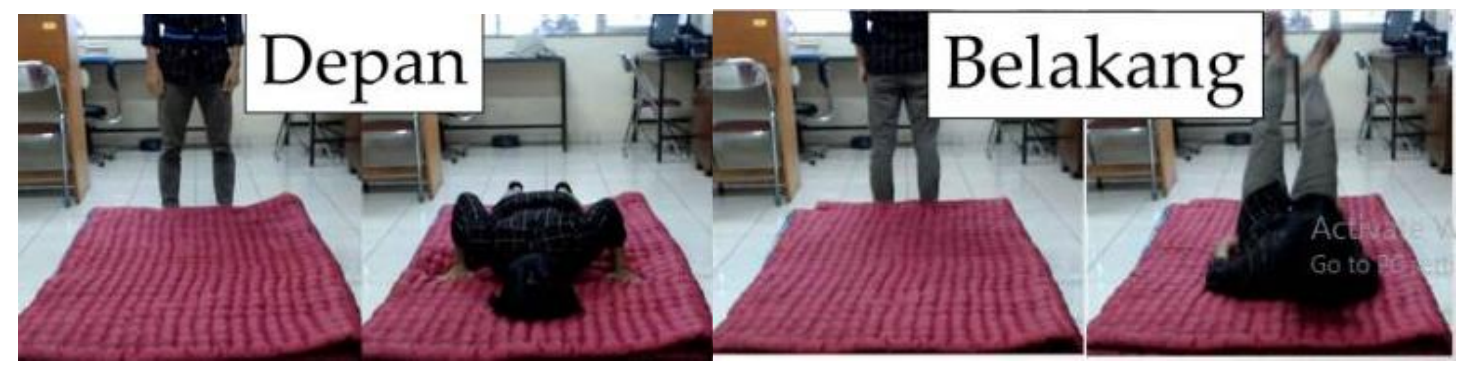

Gambar 11. Ilustrasi pengujian jatuh 
Pengambilan data dilakukan dengan menggunakan software PLX-DAQ pada PC. PLXDAQ merupakan software yang berguna untuk memindahkan data pada Serial Monitor pada program Microsoft Excel. Data yang diperoleh melalui PLX-DAQ adalah tiga sumbu accelerometer dan magnitude. Data tersebut akan dibagi menjadi 3 bagian, yakni; bagian berdiri, bagian jatuh, dan bagian jatuh steady state. Setelah diperoleh data dari ketiga bagian tersebut, selanjutnya akan dicari rata-rata dan selisih waktu yang terjadi pada tiga sumbu accelerometer dan magnitude dari masing-masing bagian tersebut. Dari hasil perbandingan tersebut dapat diketahui perbedaan karakteristik antara sikap berdiri-jatuh ke depan dan ke belakang.

\section{Hasil Pengujian}

\subsection{Kalibrasi Sensor MPU6050}

Data hasil kalibrasi sensor MPU6050 digunakan sebagai acuan dalam melakukan pengujian untuk mendapatkan hasil yang diharapkan. Proses kalibrasi dilakukan berdasarkan metodologi pengujian, yaitu sensor MPU6050 ditempatkan pada permukaan datar lalu diukur percepatan gravitasi dari masing-masing sumbu sensor. Nilai pembacaan sumbu yang menghadap pada permukaan diharapkan bernilai $1 \mathrm{~g}$ dan sumbu yang tidak menghadap permukaan diharapkan bernilai 0g. Tabel 2 menunjukkun hasil kalibrasi sensor MPU6050.

Tabel 2. Hasil kalibrasi sensor MPU6050

\begin{tabular}{|c|c|c|c|}
\hline Posisi & $\begin{array}{c}\text { Percepatan gravitasi } \\
\text { sumbu x (g) }\end{array}$ & $\begin{array}{c}\text { Percepatan gravitasi } \\
\text { sumbu y (g) }\end{array}$ & $\begin{array}{c}\text { Percepatan gravitasi } \\
\text { sumbu z (g) }\end{array}$ \\
\hline 1 & 1,00 & 0,05 & 0,02 \\
\hline 2 & 0,01 & 1,05 & 0,07 \\
\hline 3 & 0,01 & 0,00 & 1,00 \\
\hline
\end{tabular}

Berdasarkan data pada Tabel 2, hasil kalibrasi dari masing-masing sumbu terlihat mendekati dengan nilai yang diharapkan. Namun masih terdapat error pembacaan sebesar 0,01 pada sumbu x, 0,05 pada sumbu y, 0,02 dan 0,07 pada sumbu z. Error pembacaan terjadi dikarenakan sifat sensitivitas yang dimiliki sensor MPU6050. Sensitivitas tersebut terjadi karena rentang pembacaan yang dipilih adalah rentang pembacaan minimum yaitu $\pm 2 \mathrm{~g}$, dimana semakin kecil rentang pembacaan maka sensitivitas sensor terhadap perubahan posisi akan semakin besar. Faktor lainya adalah ketidakidealan komponen-komponen yang digunakan sehingga menyebabkan ketidaktepatan hasil yang pembacaan sensor yang diharapkan.

\subsection{Hasil Pengujian Kondisi Jatuh}

Pada pengujian kondisi jatuh, data yang diperoleh merupakan data sensor accelerometer yang terdiri dari empat buah data yaitu: pengukuran tiga nilai percepatan gravitasi pada sumbu $\mathrm{x}, \mathrm{y}, \mathrm{z}$, dan perhitungan nilai magnitude. Data yang telah diolah kemudian dibagi menjadi tiga kondisi, yaitu kondisi berdiri, jatuh, dan jatuh steady state. Titik a pada grafik sumbu x, y, z dan magnitude merupakan nilai kondisi berdiri pada naracoba, titik b merupakan nilai terjadinya gerakan jatuh, sedangkan titik c dan d merupakan nilai kondisi steady state pada saat jatuh.

Pada Tabel 3 ditunjukkan hasil pengujian dan pengolahan data nilai rata-rata percepatan gravitasi dan Tabel 4 menunjukkan selisih waktu antar titik pada sumbu $\mathrm{x}, \mathrm{y}, \mathrm{z}$ dan magnitude untuk 2 kondisi jatuh yaitu kondisi jatuh ke depan dan ke belakang pada 10 orang naracoba.

Tabel 3. Percepatan gravitasi sikap berdiri jatuh

\begin{tabular}{|c|c|c|c|c|c|c|c|c|}
\hline \multirow{2}{*}{ Sumbu } & \multicolumn{4}{|c|}{ Depan } & \multicolumn{4}{c|}{ Belakang } \\
\cline { 2 - 9 } & titik a & titik b & titik c & titik d & titik a & titik b & titik c & titik d \\
\hline $\mathrm{x}$ & $-0,899 \mathrm{~g}$ & $1,344 \mathrm{~g}$ & $0,166 \mathrm{~g}$ & $0,123 \mathrm{~g}$ & $-0,9 \mathrm{~g}$ & $0,87 \mathrm{~g}$ & $-0,108 \mathrm{~g}$ & $-0,085 \mathrm{~g}$ \\
\hline $\mathrm{y}$ & $-0,151 \mathrm{~g}$ & $-1,7133 \mathrm{~g}$ & $-0,483 \mathrm{~g}$ & $-0,473 \mathrm{~g}$ & $-0,217 \mathrm{~g}$ & $1,749 \mathrm{~g}$ & $0,778 \mathrm{~g}$ & $0,741 \mathrm{~g}$ \\
\hline $\mathrm{z}$ & $-0,090 \mathrm{~g}$ & $-1,916 \mathrm{~g}$ & $-0,957 \mathrm{~g}$ & $-0,889 \mathrm{~g}$ & $-0,103 \mathrm{~g}$ & $-1,703 \mathrm{~g}$ & $-0,653 \mathrm{~g}$ & $-0,657 \mathrm{~g}$ \\
\hline magntiude & $0,94 \mathrm{~g}$ & $2,916 \mathrm{~g}$ & $1,106 \mathrm{~g}$ & $1,08 \mathrm{~g}$ & 0,899 & $2,763 \mathrm{~g}$ & $1,02 \mathrm{~g}$ & $1,047 \mathrm{~g}$ \\
\hline
\end{tabular}

ISSN (e): 2540-9123

ISSN (p): 2502-1982 
Berdasarkan Tabel 3 menunjukkan bahwa pada saat jatuh ke depan, sumbu $\mathrm{x}$ bernilai positif sebesar $1,34 \mathrm{~g}$ sedangkan sumbu y dan $\mathrm{z}$ bernilai negatif sebesar $-1,71 \mathrm{~g}$ dan $-1,91 \mathrm{~g}$. Pada saat jatuh ke belakang terlihat karakteristik pada grafik berkebalikan dengan kondisi jatuh ke depan, nilai sumbu y dan $\mathrm{z}$ bernilai positif sebesar $1,37 \mathrm{~g}$ dan $1,43 \mathrm{~g}$ sedangkan sumbu $\mathrm{x}$ bernilai negatif sebesar $-1,74 \mathrm{~g}$.

Tabel 4. Selisih waktu sikap berdiri-jatuh

\begin{tabular}{|c|c|c|c|c|c|c|}
\hline \multirow{2}{*}{ Sumbu } & \multicolumn{3}{|c|}{ Depan } & \multicolumn{3}{|c|}{ Belakang } \\
\hline & $\Delta \mathbf{t}(\mathbf{a}-\mathbf{b})$ & $\Delta \mathbf{t}(\mathbf{b}-\mathbf{c})$ & $\Delta \mathrm{t}(\mathrm{c}-\mathrm{d})$ & $\Delta \mathbf{t}(\mathbf{a}-\mathbf{b})$ & $\Delta \mathbf{t}(\mathbf{b}-\mathbf{c})$ & $\Delta t(c-d)$ \\
\hline $\mathrm{x}$ & $972,067 \mathrm{~ms}$ & $363,267 \mathrm{~ms}$ & $622,2 \mathrm{~ms}$ & $1057,6 \mathrm{~ms}$ & $448,267 \mathrm{~ms}$ & $614,833 \mathrm{~ms}$ \\
\hline $\mathrm{y}$ & $459,867 \mathrm{~ms}$ & $358 \mathrm{~ms}$ & $726,1 \mathrm{~ms}$ & $691,333 \mathrm{~ms}$ & $457,667 \mathrm{~ms}$ & $758,633 \mathrm{~ms}$ \\
\hline $\mathrm{z}$ & $568,867 \mathrm{~ms}$ & $394,433 \mathrm{~ms}$ & $660,8 \mathrm{~ms}$ & $650,267 \mathrm{~ms}$ & $504,167 \mathrm{~ms}$ & $602,567 \mathrm{~ms}$ \\
\hline magnitude & $928,8 \mathrm{~ms}$ & $316,733 \mathrm{~ms}$ & $724,533 \mathrm{~ms}$ & $859,8 \mathrm{~ms}$ & $461,567 \mathrm{~ms}$ & $818,433 \mathrm{~ms}$ \\
\hline
\end{tabular}

Berdasarkan Tabel 4 menunjukkan bahwa nilai selisih waktu pada saat terjadi jatuh dari titik a ke titik b terlihat lebih lambat jika dibandingkan dengan titik b ke titik $\mathrm{c}$. Hal tersebut terjadi dikarenakan pergerakan awal naracoba yang cenderung lambat pada saat transisi dari berdiri ke jatuh. Selisih waktu dari titik c ke titik b terlihat lebih cepat dikarenakan naracoba sudah dalam transisi berdiri ke jatuh dan tidak dapat mengendalikan kecepatan tubuh. Perbedaan grafik antara percepatan gravitasi terhadap selisih waktu dapat dilihat pada Gambar 12.

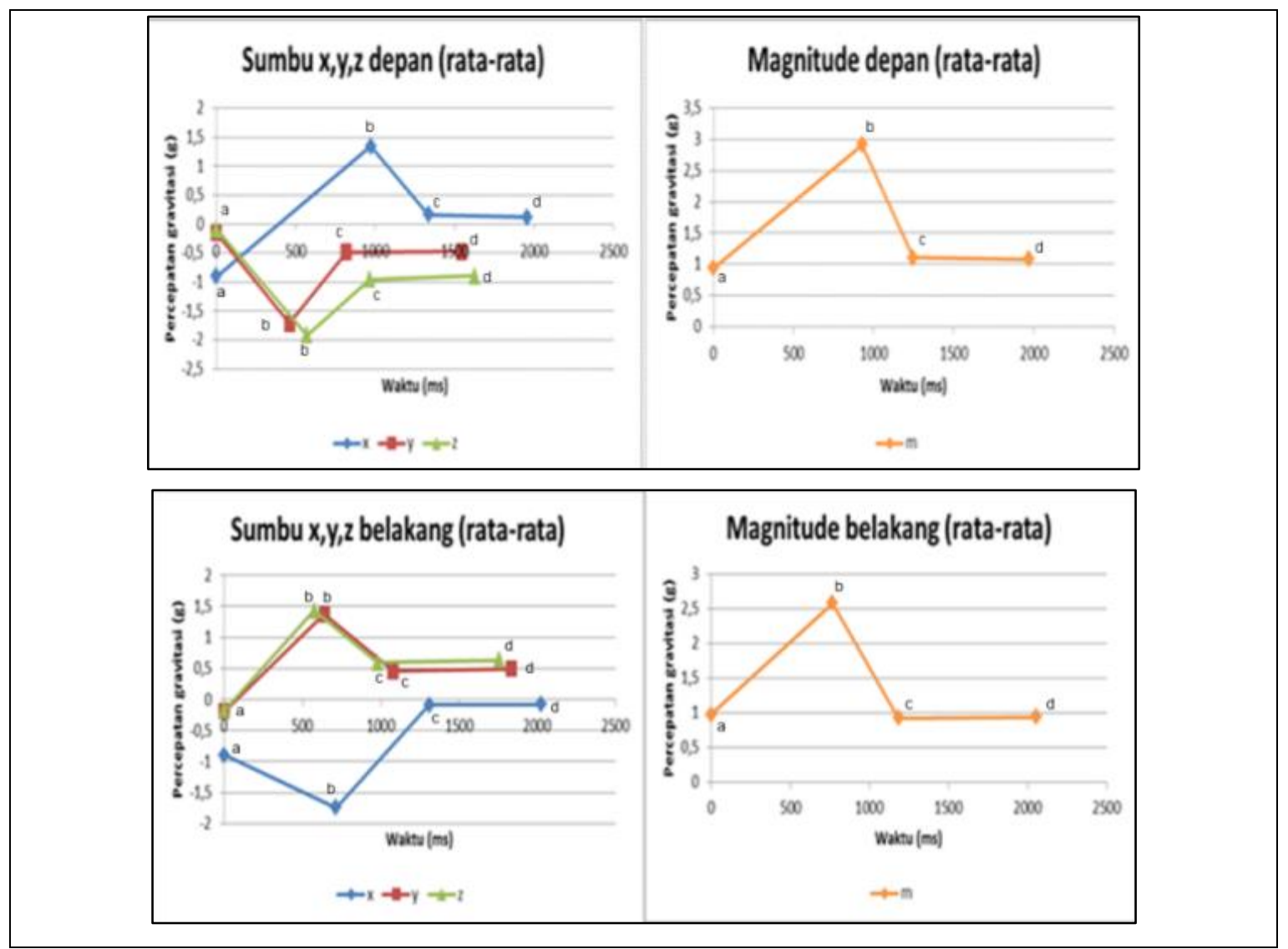

Gambar 12. Grafik tiga sumbu (x,y,z) dan magnitude kondisi jatuh dan siklus beridiri-jongkok 
Berdasarkan Gambar 12 menunjukkan nilai magnitude pada titik b yang terlihat lebih besar jika dibandingkan dengan titik-titik lainya. Hal ini terjadi karena pada saat naracoba memperagakan jatuh, terjadi pertambahan kecepatan pada saat transisi dari posisi berdiri ke posisi jatuh. Semakin cepat perpindahan posisi tersebut maka akan semakin tinggi nilai magnitude yang didapatkan.

\section{Kesimpulan}

Dari hasil pengujian dan pengolahan data terhadap sistem pendeteksi jatuh, dapat diambil beberapa kesimpulan sebagai berikut:

1. Nilai rata-rata sumbu $x$, y dan z pada posisi berdiri bernilai $-0,902 g,-0,195 \mathrm{~g}$, dan $-0,134 \mathrm{~g}$.

2. Diperoleh ciri-ciri perbedaan posisi tipe jatuh berdasarkan 3 sumbu accelerometer yaitu (Tabel 5):

Tabel 5. Ciri-ciri tipe jatuh berdasarkan 3 sumbu accelerometer

\begin{tabular}{|l|c|c|c|}
\hline Tipe Jatuh & $\mathbf{x}(\mathbf{g})$ & $\mathbf{y}(\mathbf{g})$ & $\mathbf{z}(\mathbf{g})$ \\
\hline Depan & $0,123 \pm 0,185$ & $-0,473 \pm 0,123$ & $-0,888 \pm 0,205$ \\
\hline Belakang & $-0,084 \pm 0,293$ & $0,495 \pm 0,141$ & $0,628 \pm 0,157$ \\
\hline
\end{tabular}

3. Diperoleh masing-masing nilai magnitude dan rata-rata selisih waktu jatuh untuk setiap tipe jatuh yang diuji yaitu (Tabel 6):

Tabel 6. Ciri-ciri tipe jatuh berdasarkan magnitude

\begin{tabular}{|l|c|c|}
\hline Tipe Jatuh & $\mathbf{M}(\mathbf{g})$ & $\boldsymbol{\Delta t} \mathbf{( m s )}$ \\
\hline Depan & $2,916 \pm 0,318$ & $928,8 \pm 166,209$ \\
\hline Belakang & $2,580 \pm 0,378$ & $767,383 \pm 123,795$ \\
\hline
\end{tabular}

\section{Daftar Pustaka:}

[1] Turana, Y. Stimulasi Otak pada Kelompok Lansia di Komunitas. Gambaran Kesehatan Lanjut Usia di Indonesia. (2013, July); p. 19.

[2] WHO. WHO Global Report on Falls Prevention in Older Age. Geneva: WHO. (2007).

[3] Rahman, A. Implementasi Sensor Percepatan Dan Gyroscope Untuk Menentukan Trajectory Roket Komurindo Menggunakan Inertial Navigation System (INS) Berbasis Mikrokontroler. JBPTUNIKOMPP. (2013).

[4] Ojetola, O., Gaura, E., \& Brusey, J. (2011). Fall Detection with Wearable Sensors-SAFE (SmArt Fall dEtection). IEEE.

[5] Jefiza, A., Pramunanto, E., Boedinoegroho, H., \& Purnomo, M. H. (2017). Fall Detection Based on Accelerometer and Gyroscope using Back Propagation. IEEE.

[6] InvenSense. MPU-6000 and MPU-6050 Product Specification Revision 3.4. Sunnyvale, California, United States of America. (2013, September 19).

[7] Arduino. Arduino Nano. Retrieved January 18, 2018, from Arduino: https://store.arduino.cc/usa/arduino-nano 